A. Mahdavi, F. Tahmasebi, M. Kayalar, Prediction of plug loads in office buildings: simplified and probabilistic methods, Energy \& Buildings 129 (2016) 322-329, DOI: 10.1016/j.enbuild.2016.08.022

\title{
Prediction of plug loads in office buildings: simplified and probabilistic methods
}

Ardeshir Mahdavi, Farhang Tahmasebi, Mine Kayalar

Corresponding author:

Farhang Tahmasebi

f.tahmasebi@ucl.ac.uk

Abstract: To predict buildings' energy use, multiple systems and processes must be considered. Next to factors such as building fabric and construction, indoor environmental control systems, and weather conditions, the energy demand attributable to buildings' internal heat gains resulting from inhabitants, lighting, and equipment usage also needs to be addressed. Given this background, the present contribution focuses on plug loads in office buildings associated mainly with computers and peripherals. Using long-term observational data obtained from a continuously monitored office building in Vienna, we specifically explore the relationship between inhabitants' presence, installed power for equipment, and the resulting electrical energy use. The findings facilitate the formulation of both simplified and probabilistic office plug loads predictions methods. Thereby, the model evaluation results suggest that the non-stochastic model provides fairly reasonable predictions of annual energy use associated with plug loads. However, the stochastic plug load model - together with a stochastic occupancy model outperforms the simplified model in predicting the plug loads peak and distribution. 


\section{Introduction}

Office buildings' energy demand is significant. In Europe, total annual energy use of office buildings varies roughly from 100 to $1000 \mathrm{kWh} \cdot \mathrm{m}^{-2} \cdot \mathrm{a}^{-1}$, depending on factors pertaining to location, construction, environmental control systems, as well as equipment types and use patterns [1]. Generally speaking, office buildings' energy demand is due to both provision of proper indoor conditions (e.g., heating, cooling, ventilation, lighting) and operation of office equipment. The latter energy requirement is particularly affected by inhabitants' presence and behaviour [2]. Plug loads play a significant role in office buildings, involving computers, peripheral devices, telephones, etc. A large fraction of office equipment is controlled by inhabitants [3]. Plug loads are suggested to account for more than $20 \%$ of primary energy used in office buildings, and this ratio is stipulated to increase by $40 \%$ in the next 20 years $[4,5,6]$.

Reliable estimates of plug loads are important for adequate design decision making. Specifically, building performance simulation tools geared toward assessing buildings' energy and indoor environmental performance would benefit from reliable methods to estimate plug loads magnitude [7]. The current state of knowledge (including both available information in standards and typical simulation input assumptions) with regard to the prevailing plug loads in office buildings may be characterized as not fully satisfactory.

Recently, a number of efforts have been initiated to investigate typical patterns of inhabitants' presence and actions and their impact on building performance $[8,9,10,11,12,13,14,15]$. However, there are arguably few studies regarding prediction methods of the magnitude and pattern of equipment use in office buildings. As such, only few recent studies have gone beyond the use of typical profiles of plug loads, trying to provide a deeper understanding or models of plug loads for building performance 
simulation $[16,17,18,19]$. Given this circumstance, the present contribution empirically explores presence and plug load patterns of a number of inhabitants of a selected office. The objective is to formulate a general, coherent, and transparent method to estimate office buildings' plug loads using a number of basic assumptions. Thereby, both bulk (e.g., aggregated annual values) and detailed (i.e., time-dependent high resolution) electrical energy use patterns are considered, resulting in a simplified (aggregate) and a detailed (probabilistic) prediction method. Note that, given the very small scope of the underlying empirical data, the authors do not claim the general validity of the specific formulation of the proposed prediction methods. Rather, the aim is to document the proposed approaches and illustrate their promising potential, which are to be further tested and refined via future - more extensive - cross-sectional investigations.

\section{Approach}

\subsection{Setting, research questions, and nomenclature}

The main objective of the present contribution is to explore the possibility of predicting plug loads of office buildings based on two sets of assumptions, namely the installed equipment power (specifically computers and peripherals) and the presence patterns of inhabitants. Put in general terms, we hypothesise that plug loads or electrical energy use in an office building due to office equipment can be estimated based on installed equipment power and the presence patterns of the office inhabitants.

To provide both a concise illustration and an initial test of the proposed predictive approach toward estimation of office buildings' plug loads, we selected an office area in a University building in Vienna, Austria. The area includes both single-occupancy and open-plan office rooms/zones (see Table 1). The office area is used by eight regular staff members (referred to here as U1 to U8) of different backgrounds (Department director, secretarial assistant, academic assistants, research scientists). The office area is equipped 
with a comprehensive monitoring infrastructure. Of importance are, for the purposes of the present contribution, sensors for occupancy detection and plug loads monitoring. Specifically, plug loads associated with each inhabitant (computers, peripherals, telephones, etc.) are monitored on a regular basis. To obtain occupancy data, wireless ceiling-mounted PIR sensors with EnOcean technology are used. The PIR sensor sends a value of 1 , whenever a movement is detected. If there is no movement in its detection field, the sensor sends a value of 0 every 100 seconds. Plug loads are measured via wireless energy meters, which measure active electrical energy by means of the current between input and output and transmits the consumption and meter reading over the wireless network. These sensors transmit a telegram within 20 seconds if the power status changes by minimum 10 percent. In order to facilitate data analysis, the resulting data log of occupancy and plug load was processed in terms of 15-minute intervals.

In this paper, the primary analysis and the basis for model development are based on 15-minute interval data (inhabitants' presence, plug loads) collected over a one-year period (2014). To assess the developed models' reliability, two separate sets of empirical data from the years 2013 and 2015 were complied. Note that the data included in this paper concerning the installed power of desktop computers do not directly reflect their nameplate values. Rather, they have been derived based on nameplate information according to the insights gained in previous studies. These studies suggest that desktop computers consume on average 14 to $36 \%$ of the rated values [2,20,21]. In the present treatment, we thus define a specific coefficient, which is to be applied to the nameplate values of desktop computers' installed power. 
Table 1. Overview of the selected office zones with respective inhabitants, areas, and installed power $\left(\mathrm{Q}_{\mathrm{e}}\right)$

\begin{tabular}{llll}
\hline Space & Inhabitants & $\begin{array}{l}\text { Total effective installed } \\
\text { power }[\mathrm{W}]\end{array}$ & Area $\left[\mathrm{m}^{2}\right]$ \\
\hline Open-plan office area & U1, U2, U3, U4, U5 & 880 & 43 \\
Single-occupancy office 1 & U6 & 180 & 19 \\
Single-occupancy office 2 & U7 & 90 & 34 \\
Single-occupancy office 3 & U8 & 130 & 17 \\
\hline
\end{tabular}

The collected data was analysed to address a number of salient questions:

- What is, in this case, the overall magnitude of annual person-related and arearelated plug loads and to which extend are these values in agreement with respective default values in pertinent standards?

- What is the degree of diversity amongst the inhabitants with regard to presence levels and plug loads?

- Is there a relationship between the installed equipment power and the annual energy used for electrical equipment?

- Is there an overall relationship between an inhabitants' presence probability at his/her work station and his/her energy use for electrical equipment?

- Can one establish predictive models to estimate inhabitants' equipment-related electrical energy demand based on their: i) installed equipment power, and ii) presence probability at their workstations?

To approach these questions systematically and formulate suitable prediction methods, some formal expressions can be useful as per the following nomenclature:

$P_{j, i} \quad$ Inhabitant $j$ 's presence probability (at the workplace) at time interval $t_{i}$

$Q_{j} \quad$ Installed (name-tag) plug loads at Inhabitant j's workplace

$Q_{e, j} \quad$ Effective installed plug loads at Inhabitant j's workplace

$\mathrm{q}_{\mathrm{j}, \mathrm{i}} \quad$ Inhabitant $\mathrm{j}$ 's actual plug load at time $\mathrm{t}_{\mathrm{i}}$ 
$F_{j, i} \quad$ Inhabitant $j$ 's plug load fraction at time interval $t_{i}\left(F_{j, i}=q_{j, i} / Q_{j, e}\right)$

$\mathrm{T} \quad$ Length of time interval

\subsection{Two approaches to plug load prediction}

In previous publications, we have argued that the choice of proper modelling methods in building performance simulation must take the pertinent deployment scenarios (types of queries, their purpose, and the stage at which they are formulated) into account $[22,23]$. We thus postulate that in the case of plug loads too, different computational approaches may be appropriate for different use cases. Specifically, two approaches are introduced in the present contribution. The first (simplified) approach aims as obtaining aggregate estimations such as annual plug loads in an office area or building given certain basic input data such as overall presence patterns (e.g., in terms of diversity profiles) and installed equipment power. The second (probabilistic) approach aims at emulating the stochastic nature of load fluctuations. Toward this end, high-resolution (empiricallybased or stochastically generated) time series of office inhabitants are utilised. In the following, brief descriptions of these two approaches are provided.

\subsection{The simplified approach}

We hypothesise that plug load fraction is a function of presence probability as follows:

$$
\mathrm{F}_{\mathrm{j}, \mathrm{i}}=f\left(\mathrm{p}_{\mathrm{j}, \mathrm{i}}\right)
$$

A linear version of this relationship could be represented as follows (with $a$ and $b$ as coefficients that would be empirically obtained):

$$
\mathrm{F}_{\mathrm{j}, \mathrm{i}}=a \cdot \mathrm{p}_{\mathrm{j}, \mathrm{i}}+b
$$

Given these assumptions, the energy use associated with plug loads for an office with $j$ inhabitants over a time period consisting of $n$ interval with a length of $T$ can be estimated as follows: 


$$
E=T \times \sum_{i=1}^{n} \sum_{j=1}^{m}\left(F_{j, i} \times Q_{e, j}\right)
$$

For the office area investigated in the present study and using the empirical 2014 data, this relationship can be expressed in terms of the template provided by equation 2 as follows:

$$
F_{i}=0.53 \times P_{i}+0.09
$$

\subsection{The probabilistic approach}

To explore the potential of a probabilistic approach in predicting plug loads, we formulated a simple stochastic plug load model, which utilizes three specific Weibull distributions to characterise the following:

1) Plug load fractions during occupied periods or intermediate absences shorter than one hour;

2) Plug load fractions during intermediate absences longer than one hour;

3) Plug load fractions outside working hours.

Thereby, plug load fractions are picked randomly via inverse transform sampling method, whenever the occupancy state falls within one of the above possibilities. Consequently, similar to the aforementioned simplified model, the electrical energy use can be calculated via Equation 3.

The general formulation of a Weibull distribution is as follows, where $a$ is the scale parameter and $b$ is known as the shape parameter:

$$
f(x \mid a, b)=\frac{b}{a}\left(\frac{x}{a}\right)^{b-1} e^{-\left(\frac{x}{a}\right)^{b}}
$$

Note that Weibull distribution is widely applied in various statistical modelling efforts. Specifically, formalisms based on Weibull distribution are also used in the 
occupancy-related modelling studies (see, for example, $[24,25,26]$ ). In order to obtain the parameters of the Weibull distributions, we used the monitored data pertaining to occupancy and plug loads at the studied office area in year 2014 using the maximum likelihood estimation method (see Table 2). Figure 1 illustrates cumulative distribution function of the Weibull distributions for the aforementioned cases.

Whereas the empirical distribution functions could be used to establish the stochastic model for the purpose of current study, we used the fitted Weibull distributions, so that the model can be used (and further tested by other researchers) without fully depending on high resolution monitoring data on occupancy and equipment use.

Table 2. Parameters of the stochastic plug load model's Weibull distributions (obtained from observations in the selected office area for the year 2014)

\begin{tabular}{ccc}
\hline $\begin{array}{c}\text { Model's Weibull } \\
\text { distributions }\end{array}$ & $\mathrm{a}$ (scale) & $\mathrm{b}$ (shape) \\
\hline 1 & 0.560 & 1.886 \\
2 & 0.377 & 1.323 \\
3 & 0.141 & 1.072 \\
\hline
\end{tabular}

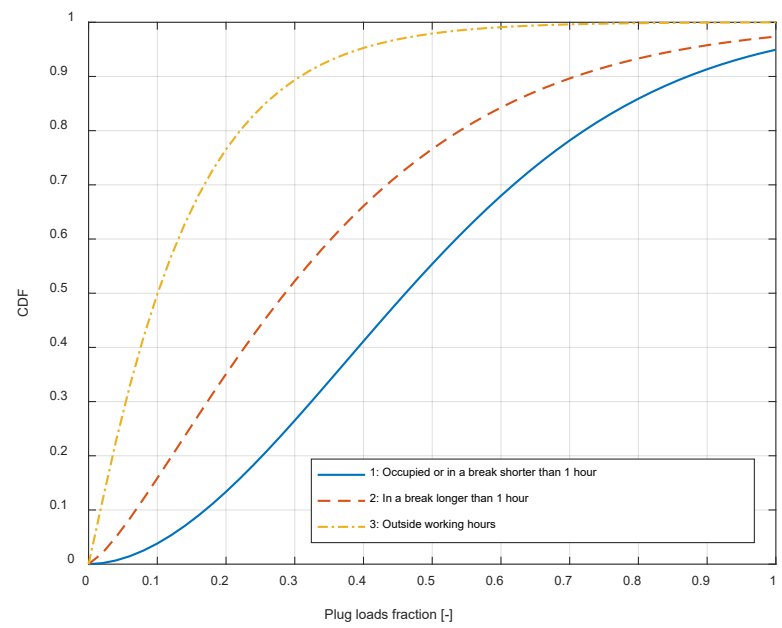

Figure 1. Cumulative distribution function of the stochastic plug load model's Weibull distributions 
It should be noted that to use this model the occupancy states (occupied or vacant) of individuals at each time interval should be provided as input. In this regard two scenarios were considered: A) Use of high-resolution monitored data for the whole running period, and B) using a stochastic occupancy model to generate non-repeating daily occupancy profiles based on limited information about occupancy patterns. While the first scenario represents a sort of ideal situation to depict the model's potential, the second scenario offers a more practical option: A number of stochastic occupancy models have been emerged, which can use relatively simple input information (i.e., observationbased or standard-based diversity profiles). For the purpose of current study, we used the stochastic occupancy model developed by Page et al. [27]. This model uses as input a profile of presence probability and average parameter of mobility $(\mu)$, which is defined as the ratio of state change probability to state persistence probability. Similar to the implementation of the linear regression model, the stochastic model was provided with average presence profiles for weekdays and weekends. Note that the model itself does not include default values for the - potentially highly influential - mobility factor. To explore the implications for the method's predictive performance, two values for mobility factor were considered, namely 0.5 and 0.1 , leading to scenarios B1 and B2 respectively. In the present contribution, we selected these values based on experiences in previous modelling studies of occupants' presence. Theoretically speaking, one could also calculate these parameter values based on the monitored occupancy data. However, the objective here was to provide a model for situations, in which only limited information about occupancy is available. Table 3 summarizes the implementation scenarios of the stochastic plug load model. 
Table 3. Implementation scenarios of the stochastic plug load model

\begin{tabular}{lll}
\hline Scenario & Input data & Coupled occupancy model \\
\hline A & Individuals' monitored occupancy data & - \\
B1 & Average monitored presence profiles for & Stochastic model [27] with $\mu=0.5$ \\
B2 & weekdays and weekends & Stochastic model [27] with $\mu=0.1$ \\
\hline
\end{tabular}

\section{Results and discussion}

\subsection{General observations}

Table 4 shows a summary of the estimated installed equipment power as well as monitored annual (work days) person-related and area-related plug loads (for the year 2014). Note that in case of U4, energy use associated with a task-light is included in the person-related and area-related plug loads. Excluding the maximum and minimum values, monitored plug loads in the selected office space was found to vary roughly between 16 and $48 \mathrm{~W} \cdot$ person $^{-1}\left(\right.$ average $=22 \mathrm{~W} \cdot$ person $\left.^{-1}\right)$. In area-related terms, this corresponds to a range of loads between 1 and $7 \mathrm{~W} \cdot \mathrm{m}^{-2}$ (mean value $=3 \mathrm{~W} \cdot \mathrm{m}^{-2}$ ). A comparison to pertinent standardized values is not possible in all cases, as standards frequently lump equipment loads together with those of lighting. ASHRAE 90.1-2013 Performance Rating Method [28], which is a widely used standard among building energy modellers, suggests a receptacle power density of $8.1 \mathrm{~W} . \mathrm{m}^{-2}$ for office buildings.

Figures 2 and 3 show, for a reference day representing the entire year, the presence probability of each inhabitant at the work station and plug load fractions respectively. This means that the loads represented in this Figure (as well as in Figures 4, 5, and 6 below) are not given in absolute terms, but in terms of the previously mentioned plug load fraction (F), i.e., actual plug load value (q) divided by the effective installed equipment power at that inhabitant's work station $\left(\mathrm{Q}_{\mathrm{e}}\right)$. We explored the relationship 
between an inhabitant's presence probability and the corresponding plug loads. Toward this end, Figure 4 shows, as an example (U7), plug load fractions as a function of the presence probability. The same relationship for all inhabitants is illustrated in Figure 5. Note that each dot in Figures 4 and 5 represents a specific 15-minute interval during a reference day (average value for all days of the year). As Figure 6 illustrates, there is considerable diversity amongst inhabitants regarding the relationship between plug load fractions and presence probability. Nevertheless, the respective correlations are high in all cases.

Figure 7 shows the relationship between each occupant's installed equipment power (in W) and the respective occupant's annual electrical equipment energy use (in $\mathrm{kWh})$. 
Table 4. Overview of person-related and area-related plug loads (annual averages, working days) based on 2014 data

\begin{tabular}{ccccc}
\hline Inhabitant & $\begin{array}{c}\text { Installed effective } \\
\text { equipment power [W] }\end{array}$ & $\begin{array}{c}\text { Monitored plug } \\
\text { loads [W] }\end{array}$ & $\begin{array}{c}\text { Allocated area } \\
{\left[\mathrm{m}^{2}\right]}\end{array}$ & $\begin{array}{c}\text { Area-related plug } \\
\text { loads [W.m }\end{array}$ \\
\hline U1 & 130 & 19.1 & 8.6 & 2.2 \\
U2 & 140 & 27.7 & 8.5 & 3.3 \\
U3 & 190 & 47.9 & 6.9 & 6.9 \\
U4 & 240 & 71.6 & 6.9 & 10.4 \\
U5 & 180 & 29.3 & 12.1 & 2.4 \\
U6 & 180 & 36.1 & 19.0 & 1.9 \\
U7 & 90 & 14.0 & 34.1 & 0.4 \\
U8 & 130 & 15.7 & 17.0 & 0.9 \\
\hline
\end{tabular}

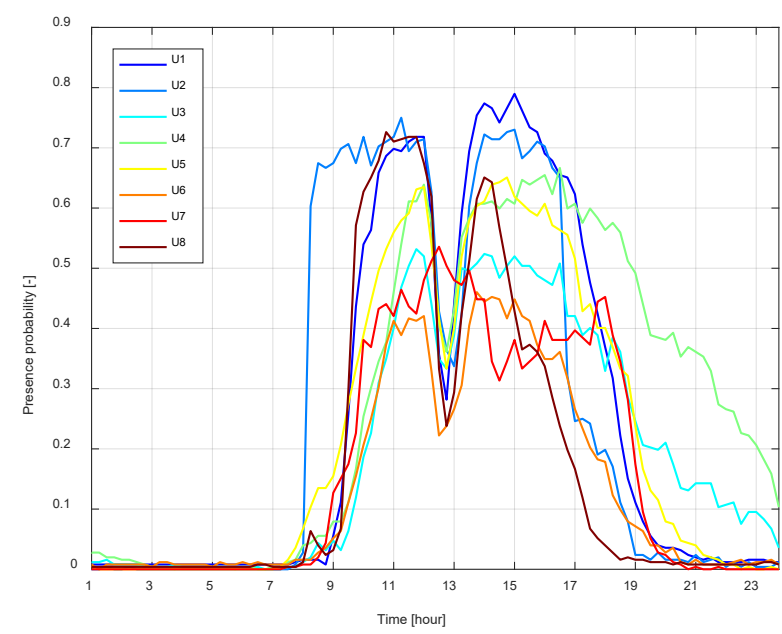

Figure 2. The eight inhabitants' presence probability for a reference day representing one year's working days

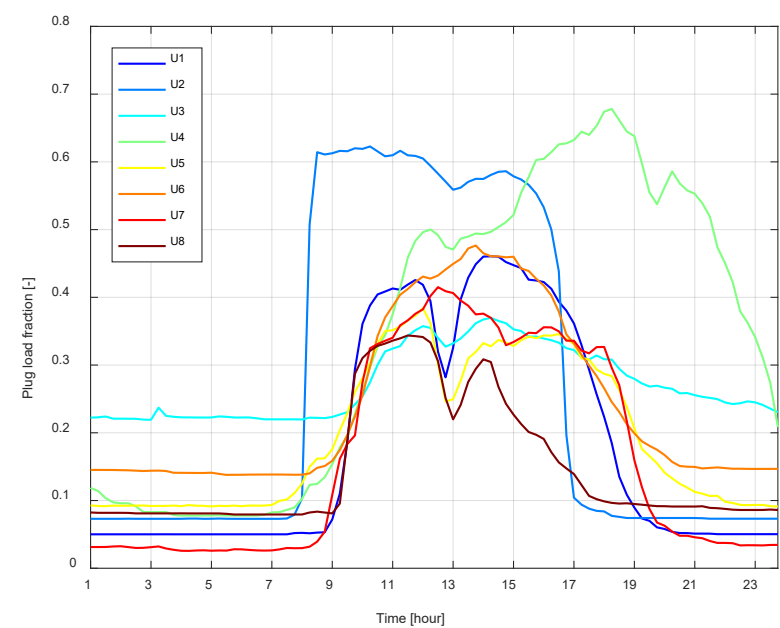

Figure 3. The eight inhabitants' plug load fractions for a reference day representing one year's working days 


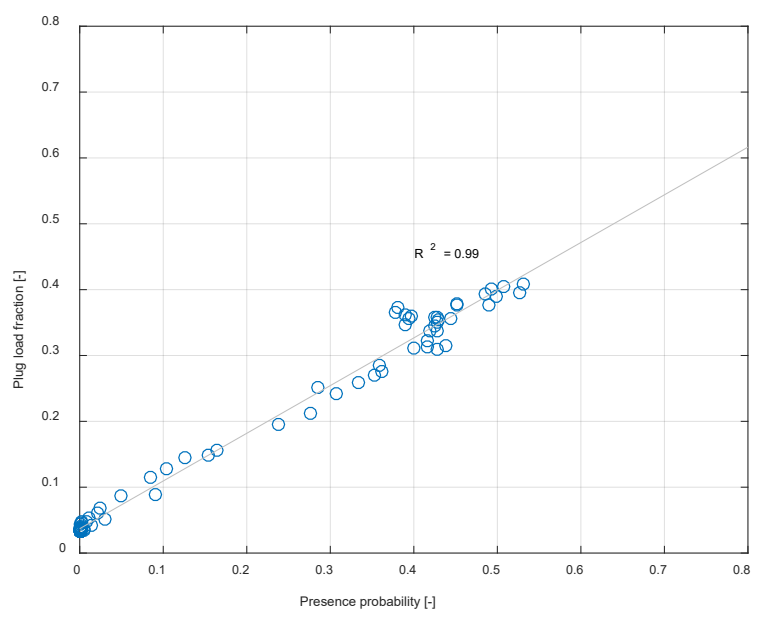

Figure 4. The relationship between inhabitant's presence probability (U7) and the plug load fraction

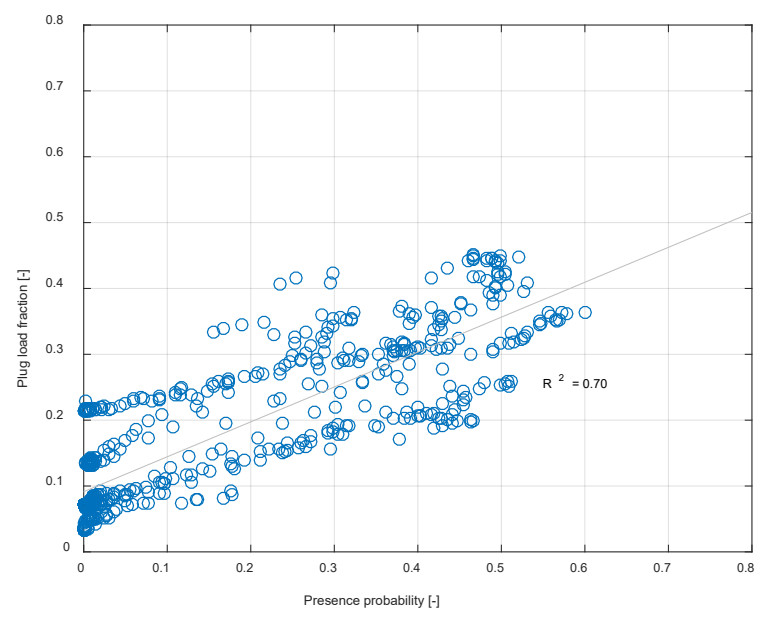

Figure 5. Linear regression analysis of the relationship between plug load fraction and presence probability for eight inhabitants

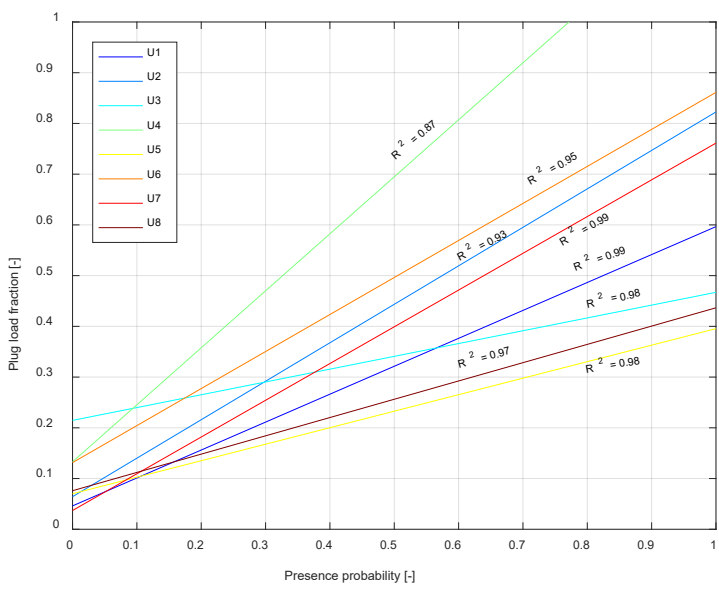

Figure 6. Linear regression analysis of the relationship between plug load fraction and presence probability for each of the eight inhabitants 


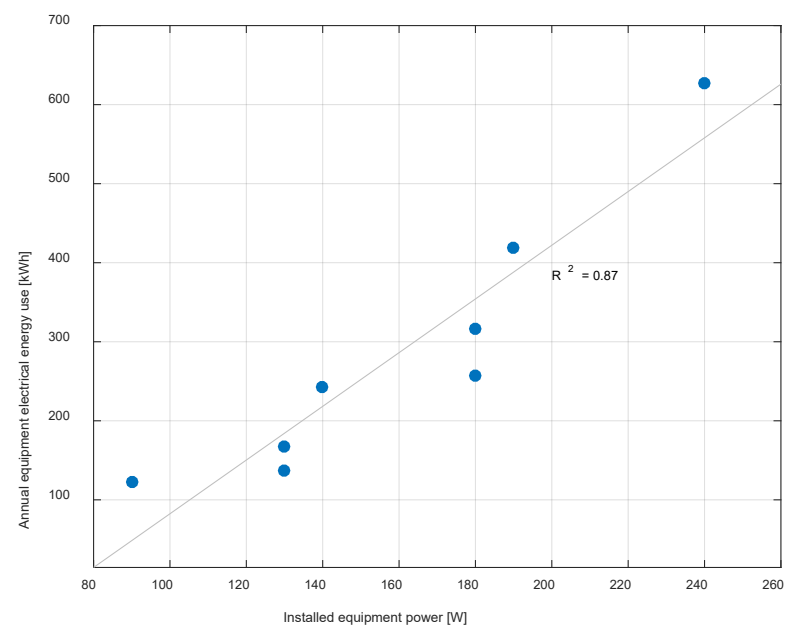

Figure 7. The relationship between annual equipment energy use and installed equipment power

\subsection{Performance of the simplified method}

As outlined in the general observations, both the presence levels and plug loads vary significantly amongst the inhabitants (see Table 4 as well as Figures 2, 3, and 6). However, there is a significant relationship between each inhabitant's presence probability at their workstations and their electrical energy use for equipment (see Figures 4,5 , and 6). This provides the highly useful practical possibility to infer each of these factors from the other. Based on data of all inhabitants, the plug load fraction $\mathrm{F}$ (the ratio of actual plug loads to the installed plug loads) can be estimated as a function of the inhabitants' presence probability P (see Equation 4).

The results also point to a significant relationship between annual energy use for electrical equipment (E) and the effective installed equipment power (see Figure 7). This suggests that the knowledge of inhabitants' presence patterns as well as the value of their installed equipment power can be used to estimate both their time-dependent and annual energy use for electrical equipment. We thus can offer a practically important tool for energy modelling efforts: Given basic assumptions regarding inhabitants' presence 
patterns and their installed equipment power, the resulting electrical energy use can be predicted - using equation 2 - with good accuracy.

As mentioned before, the empirical basis of the above analyses and the proposed methodology is limited, as it pertains to a specific office area and a small number of inhabitants. However, the employed data for model development is extensive in terms of monitoring duration and resolution (whole year data, 15-minute interval resolution). Thus, while we cannot address the robustness of the proposed approach if applied to all office buildings, it is possible to examine the model's validity if applied to monitored data from a totally separate time period. Toward this end, we compared the model's results not only with monitored data from year 2014 (which provided the empirical basis of the model) but also with two entirely separate data sets from years 2013 and 2015. In addition, to put the model's performance in a context more familiar to practitioners, we provided the electrical energy use estimations resulting from the use of ASHRAE 90.1 plug load profiles for office buildings.

Table 5 provides a summary of the monitored and calculated total and peak electrical energy use (due to office equipment) in the selected areas for the years 2014 , 2013, and 2015, together with the predictions' relative errors with reference to the measurements. In addition, to compare the distribution of predicted and monitored plug loads, we utilized the Jensen-Shannon divergence metric [29]. This metric is used to compute distances between two probability distributions and it is bounded between 0 and $\ln (2)$. For two probability distributions $\mathrm{P}$ and Q, Jensen-Shannon divergence (JSD) is calculated based on Kullback-Leibler divergence (KLD), as follows:

$J S D(P, Q)=\frac{1}{2} K L D(P, M)+\frac{1}{2} K L D(Q, M)$

Where, 


$$
M=\frac{1}{2}(P+Q)
$$

$$
K L D(P, Q)=\sum_{i} P(i) \ln \frac{P(i)}{Q(i)}
$$

Table 5 also includes the values of three statistical indicators, namely Root Mean Square error (RMSE), Normalised Root Mean Square Error (NRMSE), and Mean Bias Error (MBE) for interval by interval comparison of the monitored and calculated energy use.

These results suggest that, for the selected case study building (for which reliable information on installed equipment power and occupancy patterns was available), the proposed method can provide good predictions of the annual electrical energy use for office equipment. Interestingly, the proposed method's "predictive" performance was better for the years 2013 and 2015, even though it was developed based on the 2014 data. However, with regard to the peak plug loads and the distribution of run period predictions, the model yields relatively large errors, as it relies on average reference-day presence and plug load profiles. As compared with the use of ASHRAE 90.1 typical plug load profiles, the suggested simple model performs much better in terms of annual electrical energy use and time interval estimations of plug loads. However, the large overestimation of ASHRAE 90.1 schedules for the building under study (with a relative error of $106.7 \%$ in annual value) results in a better prediction of high peak values. 
Table 5. Statistical comparison of simplified plug load model's predictions with the monitored electrical energy use associated with plug loads for the years 2013 to 2015

\begin{tabular}{|c|c|c|c|c|c|c|c|c|c|}
\hline \multirow{2}{*}{ Model } & \multirow{2}{*}{$\begin{array}{l}\text { Run } \\
\text { period }\end{array}$} & \multicolumn{2}{|c|}{ Run period sum } & \multicolumn{2}{|c|}{ Run period peak } & \multirow{2}{*}{$\begin{array}{c}\text { Distribution } \\
\text { JSD } \\
{[-]}\end{array}$} & \multicolumn{3}{|c|}{ Time interval values } \\
\hline & & $\begin{array}{l}\text { Value } \\
{[\mathrm{kWh}]}\end{array}$ & $\begin{array}{l}\mathrm{RE} \\
{[\%]}\end{array}$ & $\begin{array}{c}\text { Value } \\
{[\mathrm{W}]}\end{array}$ & $\begin{array}{l}\mathrm{RE} \\
{[\%]}\end{array}$ & & $\begin{array}{c}\mathrm{MBE} \\
{[\mathrm{W}]}\end{array}$ & $\begin{array}{c}\text { RMSE } \\
\text { [W] }\end{array}$ & $\begin{array}{c}\text { NRMSE } \\
{[\%]}\end{array}$ \\
\hline Measured & 2014 & 2289.7 & - & 1190.9 & - & - & - & - & - \\
\hline Simplified model & 2014 & 1960.4 & -14.4 & 510.3 & -57.2 & 0.44 & -37.6 & 162.8 & 14.4 \\
\hline Measured & 2013 & 1978.0 & - & 1157.8 & - & - & - & - & - \\
\hline Simplified model & 2013 & 1958.1 & -1.0 & 513.5 & -55.6 & 0.51 & -2.3 & 129.3 & 12.0 \\
\hline Measured & 2015 & 1801.5 & - & 1058.4 & - & - & - & - & - \\
\hline Simplified model & 2015 & 1863.1 & 3.4 & 503.6 & -52.4 & 0.42 & 7.0 & 138.1 & 13.7 \\
\hline $\begin{array}{l}\text { ASHRAE } 90.1 \\
\text { plug load profiles }\end{array}$ & - & 3724.0 & 106.7 & 1152.0 & 8.8 & 0.40 & 219.5 & 415.2 & 41.1 \\
\hline
\end{tabular}

\subsection{Performance of the probabilistic method}

As shown in Table 6, the stochastic method's performance in predicting annual, peak, and time interval plug loads was evaluated in the same manner. However, in case of the stochastic model, the values provided in Table 6 are mean values of a 100-run Monte Carlo simulation of the model. In addition, as explained before, the stochastic plug load model was implemented in 3 different scenarios in terms of input occupancy data (see Table 3).

The results provided in Table 6 suggest that the implemented stochastic method for office plug loads does not provide very accurate predictions of the annual electrical energy use. However, it provides fairly good estimations of peak loads. It should be also considered that, despite the poor performance in terms of annual use predictions, it still outperforms the ASHRAE 90.1 profiles in terms of all our evaluation metrics. 
Considering different implementation scenarios of the stochastic plug load model, it can be seen that the selection of input parameters for the stochastic occupancy model (in this study the parameter of mobility), has a large impact on the resulting energy use predictions. Specifically, for the office area studied here, setting the parameter of mobility to 0.5 results in a large overestimation of annual plug loads. However, when using a parameter of mobility of 0.1 , model predictions converge to those obtained via high resolution occupancy data input.

Table 6. Statistical comparison of stochastic plug load model's predictions with the monitored electrical energy use associated with plug loads for the years 2013 to 2015

\begin{tabular}{|c|c|c|c|c|c|c|c|c|c|}
\hline \multirow{2}{*}{ Model } & \multirow{2}{*}{$\begin{array}{l}\text { Run } \\
\text { period }\end{array}$} & \multicolumn{2}{|c|}{ Run period sum } & \multicolumn{2}{|c|}{ Run period peak } & \multirow{2}{*}{$\begin{array}{c}\text { Distribution } \\
\text { JSD } \\
{[-]}\end{array}$} & \multicolumn{3}{|c|}{ Time interval values } \\
\hline & & $\begin{array}{l}\text { Value } \\
{[\mathrm{kWh}]}\end{array}$ & $\begin{array}{l}\mathrm{RE} \\
{[\%]}\end{array}$ & $\begin{array}{l}\text { Value } \\
{[\mathrm{W}]}\end{array}$ & $\begin{array}{l}\mathrm{RE} \\
{[\%]}\end{array}$ & & $\begin{array}{l}\mathrm{MBE} \\
{[\mathrm{W}]}\end{array}$ & $\begin{array}{c}\text { RMSE } \\
\text { [W] }\end{array}$ & $\begin{array}{c}\text { NRMSE } \\
{[\%]}\end{array}$ \\
\hline Measured & 2014 & 2289.7 & - & 1190.9 & - & - & - & - & - \\
\hline $\begin{array}{l}\text { Stochastic model, } \\
\text { Scenario B1 }\end{array}$ & 2014 & 2904.5 & 26.9 & 1092.3 & -8.3 & 0.34 & 70.2 & 199.4 & 17.6 \\
\hline $\begin{array}{l}\text { Stochastic model, } \\
\text { Scenario B2 }\end{array}$ & 2014 & 2388.1 & 4.3 & 1018.1 & -14.5 & 0.35 & 11.2 & 182.7 & 16.2 \\
\hline $\begin{array}{l}\text { Stochastic model, } \\
\text { Scenario A }\end{array}$ & 2014 & 2424.3 & 5.9 & 1033.5 & -13.2 & 0.33 & 15.4 & 141.5 & 12.5 \\
\hline Measured & 2013 & 1978.0 & - & 1157.8 & - & - & - & - & - \\
\hline $\begin{array}{l}\text { Stochastic model, } \\
\text { Scenario B1 }\end{array}$ & 2013 & 2835.6 & 43.4 & 1098.6 & -5.1 & 0.37 & 97.9 & 209.4 & 19.4 \\
\hline $\begin{array}{l}\text { Stochastic model, } \\
\text { Scenario B2 }\end{array}$ & 2013 & 2354.8 & 19.1 & 1007.5 & -13.0 & 0.38 & 43.0 & 181.7 & 16.9 \\
\hline $\begin{array}{l}\text { Stochastic model, } \\
\text { Scenario A }\end{array}$ & 2013 & 2374.3 & 20.0 & 1057.8 & -8.6 & 0.36 & 45.3 & 123.2 & 11.4 \\
\hline Measured & 2015 & 1801.5 & - & 1058.4 & - & - & - & - & - \\
\hline $\begin{array}{l}\text { Stochastic model, } \\
\text { Scenario B1 }\end{array}$ & 2015 & 2782.7 & 54.5 & 1091.9 & 3.2 & 0.34 & 112.0 & 205.0 & 20.3 \\
\hline $\begin{array}{l}\text { Stochastic model, } \\
\text { Scenario B2 }\end{array}$ & 2015 & 2333.5 & 29.5 & 1004.1 & -5.1 & 0.34 & 60.8 & 175.2 & 17.3 \\
\hline $\begin{array}{l}\text { Stochastic model, } \\
\text { Scenario A }\end{array}$ & 2015 & 2322.7 & 28.9 & 1009.8 & -4.6 & 0.33 & 59.5 & 137.3 & 13.6 \\
\hline $\begin{array}{l}\text { ASHRAE } 90.1 \text { plug } \\
\text { load profiles }\end{array}$ & - & 3724.0 & 106.7 & 1152.0 & 8.8 & 0.40 & 219.5 & 415.2 & 41.1 \\
\hline
\end{tabular}




\section{Conclusion}

Knowledge about inhabitants' presence and behaviour in buildings can yield better (simulation-based) estimations of energy use and improve the building design and operation process. In the present contribution, we used actual monitoring results to address a number of relevant questions regarding plug loads in office buildings. The results suggest that the observed loads in the selected office do not necessarily correspond to common assumptions in standards and simulation input data. Moreover, patterns of user presence and plug load requirements differ significantly amongst individual office users.

The results point also to an interesting and potentially highly useful relationship between inhabitants' presence, their respective installed equipment power, and the resulting electrical energy use. Using this relationship, we proposed and tested a simplified (aggregate) and a detailed (probabilistic) method for the prediction of electrical energy use in buildings due to office equipment operation.

The comparison of model predictions with observed data facilitates a number of conclusions. The simplified method provides fairly reasonable predictions of annual energy use associated with plug loads. Indeed, the performance of the simplified model was in this regard considerably better than the more sophisticated probabilistic model implementations in the validation years 2013 and 2015 (see Figure 8). However, the probabilistic plug load model, independent of the variations implemented, outperforms the simplified model in terms of peak load (see Figure 9) and the distribution of predictions. The latter can be inferred from the lower values of JSD (see Table 5 and Table 6) and is clearly illustrated for year 2013 in Figure 10. With regard to the time interval plug loads, comparing the models with the same level of input (the simplified 
model versus the probabilistic model in implementation scenarios B1 and B2), reveals a better performance on the side of the simplified model.

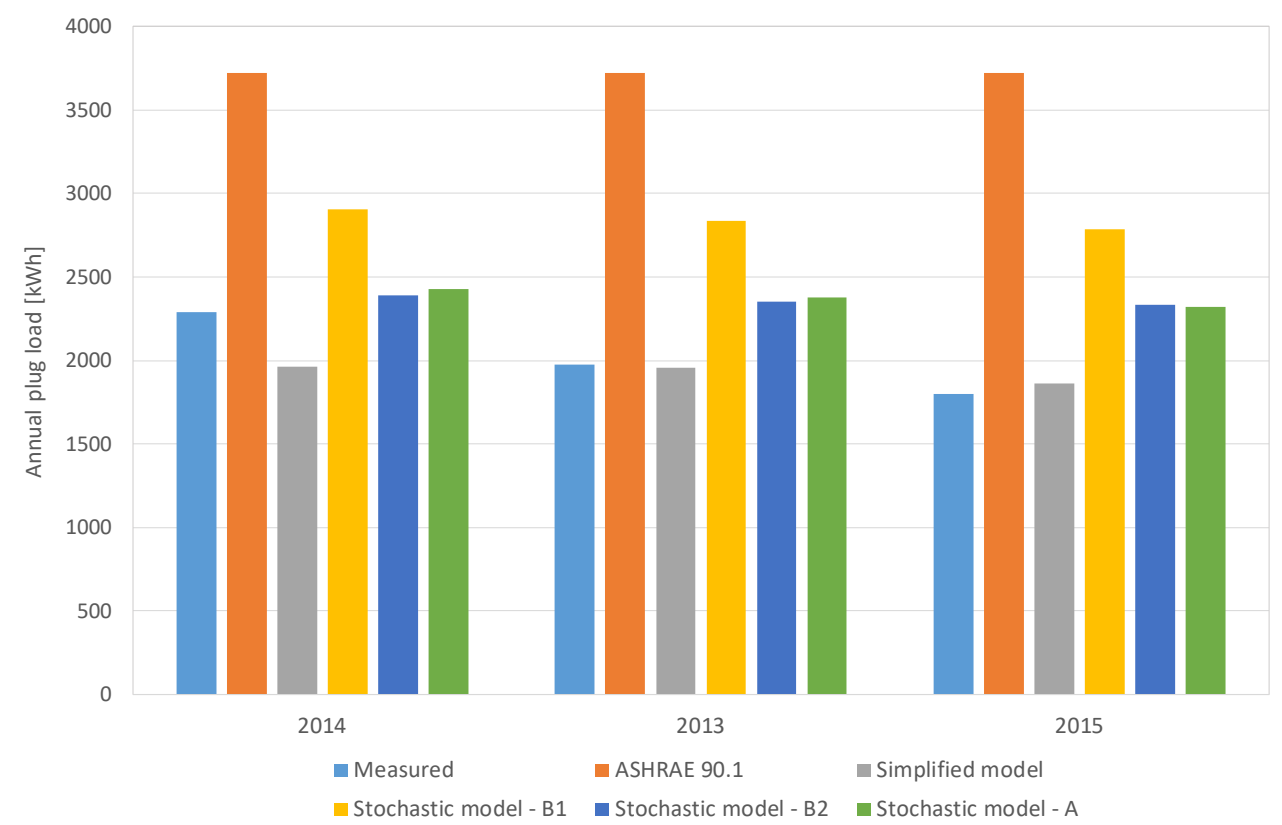

Figure 8. Annual plug load obtained from different modelling approaches, along with the respective monitored values

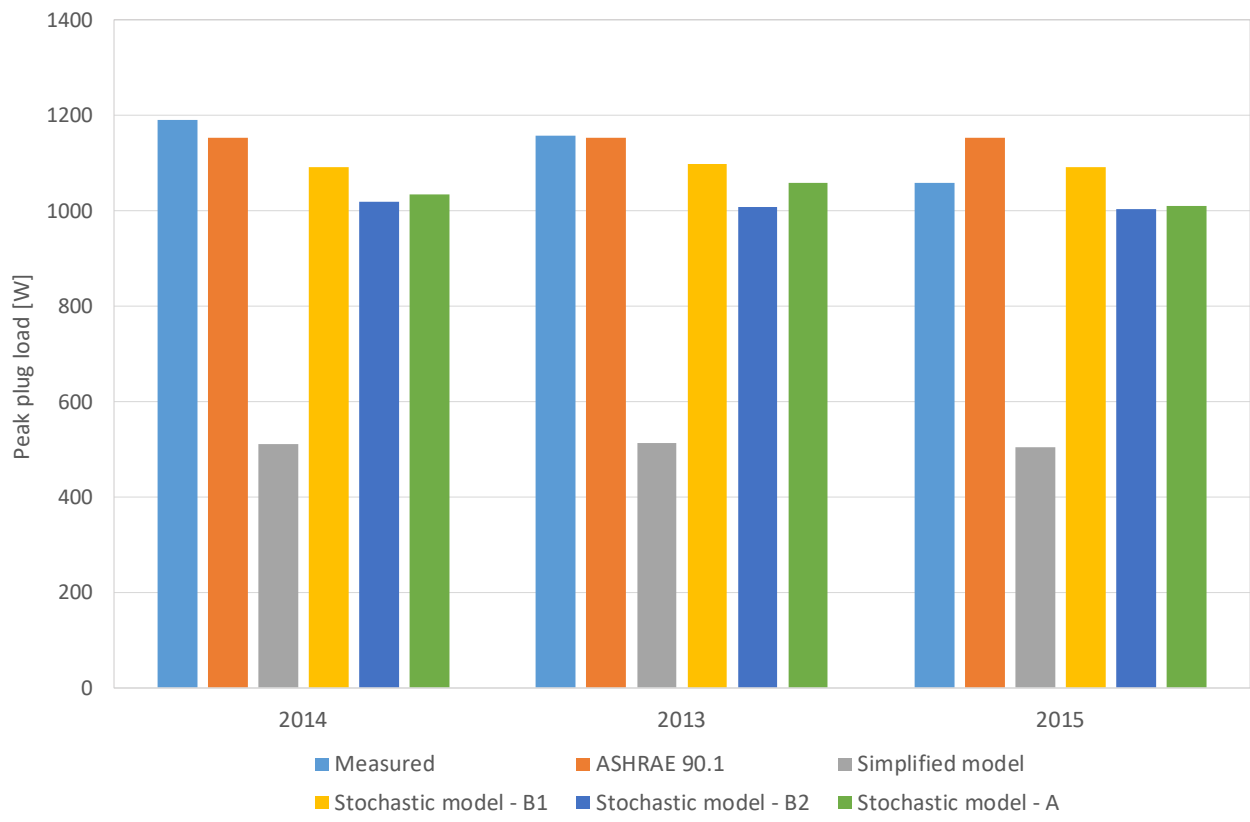

Figure 9. Peak plug load obtained from different modelling approaches, along with the respective monitored values 


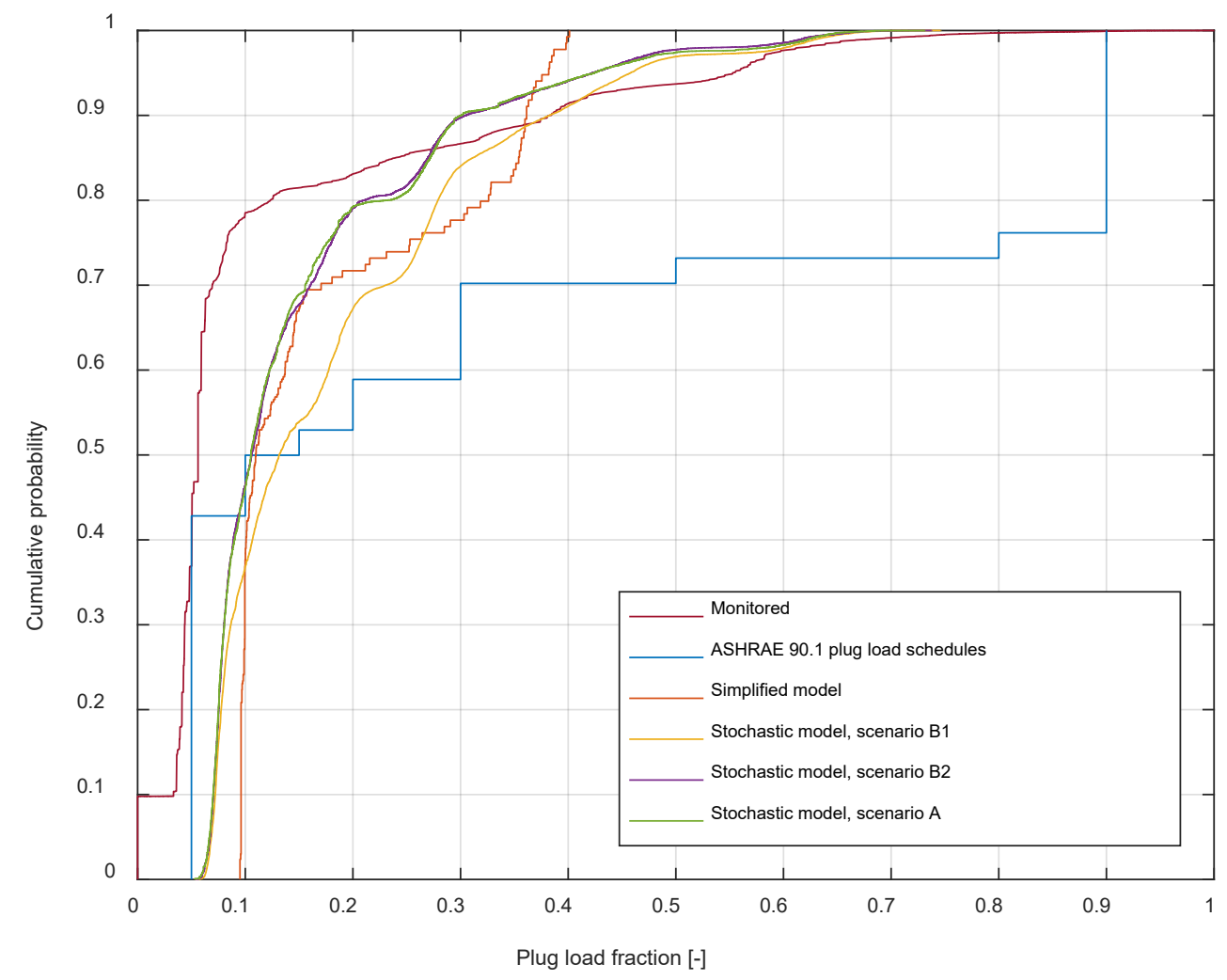

Figure 10. Cumulative distribution of plug load fraction obtained from different modelling scenarios for year 2013, along with the respective monitored values

Our main objective in this paper was to conceive and implement the general structure of predictive methods for office plug loads. This was accomplished in terms of both a simplified method and a more detailed probabilistic method. These initial implementations proved to be promising, whereby the choice of the appropriate model may be dependent on the deployment scenario: Whereas the simplified (aggregate) model's predictions came closer to observed annual energy use values, probabilistic models performed better in prediction of peak plug loads and in emulation of timedependent (interval) data distributions.

As stressed before, the present study was based on a limited set of empirical data obtained from one office area. While we consider the general mathematical formulation of the proposed prediction methods to be both consistent and promising, we do not 
suggest that they could be generally applied without proper adjustment and calibration measures, pertaining, for example, to the values of various coefficients and parameters involved. Ongoing and future - more extensive - cross-sectional investigations in this area are expected to utilise a larger empirical foundation and thus lead to more representative and inclusive model iterations that could be embedded in high resolution building performance modelling and energy simulation applications.

\section{References}

[1] D. Caccaveli, H. Gugerli, TOBUS - A EU diagnosis and decision making tool for office building upgrading, Energy and Buildings, 34, 2002, pp.113-119.

[2] Z. Wang, Y. Ding, Occupant-based energy consumption prediction model for office equipment, Energy and Buildings, 109, 2015, pp.12-22

[3] K. McKenney, M. Guernsey, R. Ponoum, J. Rosenfeld, Commercial miscellaneous electric loads: energy consumption characterization and savings potential in 2008 by building type, Technical report D498, DOE, Building Technologies Program, 2010.

[4] Office of Energy Efficiency and Renewable Energy, U.S. Department of Energy, Buildings energy data book, 2011.

[5] K. Roth, K. Mckenny, C. Paetsch, R. Ponoum, US residential miscellaneous electric loads electricity consumption, In: ACEEE study on energy efficiency in buildings, 2008.

[6] G. Ghatikar, H.I. Cheung, S. Lanzisera, Miscellaneous and electronic loads energy efficiency opportunities for commercial buildings: a collaborative study by the United States and India, Lawrence Berkeley National Laboratory and Infosys Technologies Limited, 2013.

[7] D. Yan, W. O'Brien, T. Hong, X. Feng, H.B. Gunay, F. Tahmasebi, A. Mahdavi, Occupant behaviour modelling for building performance simulation: Current state and future challenges, Energy and Buildings, 107, 2015, pp. 264-278.

[8] F. Tahmasebi, A. Mahdavi, The sensitivity of building performance simulation results to the choice of occupants' presence models: a case study, Journal of Building Performance Simulation, (2015), doi:10.1080/19401493.2015.1117528.

[9] F. Tahmasebi, A. Mahdavi, An inquiry into the reliability of window operation models in building performance simulation, Building and Environment 105 (2016) 343-357, doi:10.1016/j.buildenv.2016.06.013.

[10] X. Feng, D. Yan, T. Hong, Simulation of occupancy in buildings, Energy and Buildings 87 (2015) 348-359, doi:10.1016/j.enbuild.2014.11.067.

[11] P. Hoes, J.L.M. Hensen, M.G.L.C. Loomans, B. de Vries, D. Bourgeois, User behavior in whole building simulation, Energy and Buildings 41 (2009), pp. 295-302. doi:10.1016/j.enbuild.2008.09.008.

[12] S. D'Oca, V. Fabi, S.P. Corgnati, R.K. Andersen, Effect of thermostat and window opening occupant behavior models on energy use in homes, BUILD SIMUL (2014) 7: 683-694, DOI 10.1007/s12273-014-0191-6. 
[13] Q. Wang, G. Augenbroe, J-H. Kim, L. Gu, Meta-modeling of occupancy variables and analysis of their impact on energy outcomes of office buildings, Applied Energy 174 (2016) 166-180, doi:10.1016/j.apenergy.2016.04.062.

[14] T. Hong, H-W. Lin, Occupant Behavior: Impact on Energy Use of Private Offices, ASim 2012 - 1st Asia conference of International Building Performance Simulation Association, Tongji University Press, 2012.

[15] A. Mahdavi, F. Tahmasebi, Predicting people's presence in buildings: An empirically based model performance analysis, Energy and Buildings 86 (2015) 349-355, doi:10.1016/j.enbuild.2014.10.027.

[16] H.B. Gunay, W. O'Brien, I. Beausoleil-Morrison, S. Gilani, Modeling plug-in equipment load patterns in private office spaces, Energy and Buildings 121 (2016) 234-249, doi:10.1016/j.enbuild.2016.03.001.

[17] P. Gandhi, G.S. Brager, Commercial office plug load energy consumption trends and the role of occupant behavior, Energy and Buildings 125 (2016) 1-8, doi:10.1016/j.enbuild.2016.04.057.

[18] R. Reddy, K. Niranjan, A. Swaroopa, V. Garg, Plug Loads: Usage and Energy Consumption Analysis, ASim2014 Proceedings, pp. 196-203.

[19] A.C. Menezes, A. Cripps, R.A. Buswell, J. Wright, D. Bouchlaghem, Estimating the energy consumption and power demand of small power equipment in office buildings, Energy and Buildings 75 (2014) 199-209, doi:10.1016/j.enbuild.2014.02.011.

[20] M.H. Hosni, Test method for measuring radiant/convective split of heat gains from equipment in buildings, ASHRAE Research Project, 822, 1997.

[21] B.W. JONES, Measurement of heat gain and radiant convective split from equipment in buildings, ASHRAE Research Project, 1055, 1997.

[22] A. Mahdavi, F. Tahmasebi, The deployment-dependence of occupancy-related models in building performance simulation, Energy and Buildings 117 (2016) 313-320, doi:10.1016/j.enbuild.2015.09.065.

[23] I. Gaetani, P. Hoes, J.L.M. Hensen, Occupant behavior in building energy simulation: Towards a fit-for-purpose modeling strategy, Energy and Buildings 121 (2016) 188-204, doi:10.1016/j.enbuild.2016.03.038.

[24] T. Hong, S.C. Taylor-Langea, S. D’Oca, D. Yan, S.P. Corgnati, Advances in research and applications of energy-related occupant behavior in buildings, Energy and Buildings 116 (2016) 694-702, doi:10.1016/j.enbuild.2015.11.052.

[25] T. Hong, H. Sun, Y. Chen, S.C. Taylor-Langea, D. Yan, An occupant behavior modeling tool for co-simulation, Energy and Buildings 117 (2016) 272-281, doi:10.1016/j.enbuild.2015.10.033.

[26] F. Haldi, D. Robinson, Interactions with window openings by office occupants. Building and Environment, 44(2009), pp 2378-2395, doi:10.1016/j.buildenv.2009.03.025.

[27] J. Page, D. Robinson, N. Morel, J.L. Scartezzini, A generalized stochastic model for the simulation of occupant presence, Energy and Buildings 40 (2): 83-98. doi:10.1016/j.enbuild.2007.01.018.

[28] ASHRAE, ASHRAE 90.1-2013: Energy Standard for Buildings Except Low-Rise Residential Buildings, American Society of Heating, Refrigerating and Air-Conditioning Engineers, Inc., Atlanta, 2013.

[29] J. Lin, Divergence Measures Based on the Shannon Entropy, IEEE Transactions on information theory, Volume 37, No. 1, January 1991. 